\title{
The integration of universal design in interior design as a green design approach for diverse users in Malaysia
}

\begin{abstract}
Significant changes in the world population demand interior design approach to be more usable and accessible for all people. However, the lack of awareness and misinterpretation on the "real user" during interior design process discourage the integration of Universal design (UD) in the built environment. For that reason, this study employed literature survey to identify how UD principles could support diverse users in the built environment. Then, we recognize how UD can be employed in the interior design process to meet this purpose. The results of this study contribute in recommending the integration of UD as a green interior design approach for accommodating diverse user in the Malaysian built environment.
\end{abstract}

Keyword: Integrated design; Universal design; Interior design; Usable design 